\title{
UMA ENTREVISTA COM O DR. CLEMENTE FERREIRA
}

Tendo-se realisado uitimamente a inauguração do sanatorio para tuberculosos em São José dos Campos - a realisação de maior vulto na lucta contra a tuberculose - , achámos orppcrtuno trazer para os leitores a opinião do dr. Clemente Ferreira sobre o problema da tuberculose em S. Paulo.

De facto, ninguem mais autorisado para se manifestar sobre tal assumpto. O dr. Clemente Ferreira é o maior paladino da campanha que entre nós se realisa contra aquelle mal, o apostolo mais devotado de quantos uma in:ciativa nobre possa ter tido.

O dr. Clemente Ferreira é um caso impressionante de abregação e devotamento. Vem elle mantendo uma lucta sem treguas contra a tuberculose, lucta em que sua melhor arma é a propria dedicação, e em que são inimigos temerosos o mal que se propõe a combater, mais uma calamitosa indifferença por parte do governo e por parte do publico.

Em se tratando do apoio official, ențão, está-se, ha annos, assistindo a uma aposta interessante. De um lado a indifferença do governo, rigida, maciça, incompressivel, inabalavel, a jurar que nada fará contra a tuberculose; de outro lado a actividade do dr. Clemente Ferreira, serena, imperturbavel, tenaz, a jurar, por sua vez, que reduzirá a tuberculose ás condições de uma fera enjaulada.

O resultado da aposta? Não o sabemos. Dizem por ahi que a fé move montanhas. Talvez, quando a montanha não é esse Hymalaia da indifferença official.

$\mathrm{O}$ dr. Clemente Ferreira não conta senão com um auxilio certo - comsigo mesmo. Como recompensa não terá mais que as bençams dos que elle protege. Bençams, dizem os entendidos em cousas da vida pratica, não enchem barriga. Não importa. O dr. Clemente Ferreira é daquelles privilegiados que se satisfazem com a consciencia do dever cumprido. E este, pode s. s. ficar tranquillo, está sendo cumprido como talvez nenhum outro tenha sido.

- Queriamos, dr. Clemente Ferreira, sua opinião sobre o problema da tuberculose em São Paulo.

- Encarado por sua face prophylactica ou curativa? O problema tem esses dois aspectos, ambos importantissimos, que se 
embricam mutuamente. A face prophylactica do problema tem maior importancia, pois sua solução cabal daria m resultade o desaprarecimento da segunda.

- Queriamos precisamente a importancia do nuvo sanatrsio em são José dos Campos.

- E' grande; é um notavel subsidio á campanha contra a tuberculose particularmente do ponto de vista da assistencia. Sob o angulo prophylactico, porém, a o qual ligamos a maxima importancia, seu papel é restricto. Como isolamento, tambem, é pouco, pois, para os vinte mil doentes que devemos ter em todo o Estado, offerece elle duzentos leitos. Entretanto, por seu aspecto de sanatorio, pode prestar muito serviço, abrigando doentes ainda passiveis de cura, dando-lhes educação hygienica, e ao mesmo tompo, isolando da communhão social doentes que são elementos for ‘́emente contagiantes.

- Deste modo, os sanatorios são a melhor arma de combate contra a tuberculose?

- Longe disso. O meio ideal de lucta são os preventorios para creanças, os dispensarios para adultos e os sanatorios diurnos, nos quaes o doente passa apenas o dia, e que são de baixo custo e de economica manutenção. Aliás, nesse particular de assistencia prophylactica estamos num atrazo lamentavel. A Allemanha, em tempos normaes, contava com 2.000 dispensarios, 317 hospitaes para isolamento de doentes, 70 sunatorios, 9.500 leitos para crianças fracas, 82 hospitaes para observação e 120 hospitaes florestaes para convalescentés. C'om uma organisação dossas é possivel fazer-se campanha contra a tuberculose. Mas, no meio de todo esse apparelhamento, o dispensario é que culmina em importancia e valor. Como o sr. sabe, o maior contingente de tuberculosos é fornecido pelas classes pobres, que não só não tèm recursos para procurar um medico, como, tambem, continuam a trabalhar mesmo depois de se sentirem doentes. Dahi duas consequencias - primeiramente, o contagio dos sãos; depois, perderem a opportunidade de cura, de modo que quando recorrem ao medico estão já inutilisados para o trabalho. Pois bem - ahi é que o dispensaric se revela em toda a magnitude de seu valor e importancia. Installado nos centros de população proletaria, de accesso fảcil para os que delle precisam, fornecendo gratuitamente os seus serviços, é no mais forte reducto da molestia que elle vae agir. Agindo sobre as classes mais sujeitas a.o mal, elle distribue ampla educação hygienica, reformando, assim, o meio em que vivem taes individuos. Além disso, fazendo systematicamente o exame de seus clientes, apanha a molestia em suas primeiras manifestações, isto é, quando o mal ainda é um mal de cura, e impedindo que esses doentes se tornem infectantes. Ahi 
é que o sanatorio vem completar a aç̧ão do dispensario, recebendo e assistindo aos doentes que este lhe envia.

- Assim, o sanatorio de São José dos Campos veiu um pouco antes da hora, isto é, antes dos dispensarios que lhe deviam enviar os doentes?

- Não direi isso. E' grande o serviço que pode prestar, sendo, como é, o primeiro estabelecmeinto de cura que se abre abre para os tuberculosos; embora menor do que o que prestariam aos operarios os dispensarios na capital e no interior, muito menos dispendiosos e de acção mais ampla, mais preservadora, por mais opportuna e sobretudo por poderem exercer a sua acção nas zonas, nas regiões em que a molestia fôr mals devastadora. O sanatovio, em sua construcção, deve fugir ao luxo, pois se não o doente pobre, quando delle sae, sente a nostalgia do conforto da vida que lá levava, e faz o possivel para voltar. Como companheiro do dispensario, temos o preventorio. Este realisa prophylaxia mais ampla, pois preserva a creança desde o nascimento, subtrahindo-a ao contagio familiar e aguerindo as crianças debeis, taradas e predispostas, exercendo, portanto, uma acção social e sanitaria de amplissima projeção. Temos apenas um preventorio no Estado,. em Bragança; mas para a população infantil, debil, constituida pela prole dos tuberculosos, é quasi nada. A acção do preventorio é notavel. Nas filiaes da obra de Grancher, em França, em 2500 creanças occorreram 7 obitos; em Bragança, em 500 creanças alli admittidas e fortalecidas, apenas houve um caso de manifestação do mal. A aç̧ão dos dispensarios se completa com a aç̧ão dos sanatorios, mesmo diurnos, e principalmente sub-urbanos. No anno passado demos alta, no Dispensario da Liga Contra a Tuberculose, a 170 doentes apparentemente curados; se tivessemos um sanatorio popular, ra peripheria da cidade, essas curas apparentes poderiam se consolidar. A acção dos preventorios, como lhe disse é immensa, pois furta ao meio contagiante creariças geralmente já em condições pouco satisfactorias de robustez, e algumás com lesões bacillares latentes. Ha um facto eloquente a esse respeito. Das creanças abrigadas no preventorio de Bragança aigumas foram, quando em edade sufficiente, ser marizheiros! Isto é, creanças fatalmente condemnadas á tuberculose, puderam, graças á acção do preventorio, se entregar a um officio que exige o maximo de robustez e saude. Vê o sr. que a acção dos estabelecimentos de lucta contra o ma? é positiva. Prasa acs ceus voltem os governos slias vistas e seu apoio á campanha contra a tuberculose, e terão elles realisado obra patriotica e meritoria. 